\section{(2) OPEN ACCESS}

\title{
Medical expenditure after marginal cut of cash benefit among public assistance recipients in Japan: natural experimental evidence
}

\author{
Daisuke Nishioka (1) , ${ }^{1,2,3}$ Reo Takaku, ${ }^{4}$ Naoki Kondo (i) 2,3,5,6
}

\begin{abstract}
- Additional supplemental material is published online only. To view, please visit the journal online (http://dx. doi.org/10.1136/jech-2021217296)
\end{abstract}

'Department of Medical Statistics, Osaka Medical and Pharmaceutical University, Takatsuki, Japan

${ }^{2}$ Department of Health and Social Behavior, The University of Tokyo, Bunkyo-ku, Japan ${ }^{3}$ Department of Social Epidemiology, Kyoto University, Kyoto-shi, Kyoto, Japan ${ }^{4}$ Graduate School of Economics and School of International and Public Policy, Hitotsubashi University, Kunitachi, Japan ${ }^{5}$ Institute for Future Initiatives, The University of Tokyo, Bunkyoku, Japan

${ }^{6} J a p a n$ Agency for

Gerontological Evaluation Study (JAGES Agency), Taito-ku, Japan

\section{Correspondence to}

Professor Naoki Kondo, Department of Social Epidemiology, Kyoto University, Kyoto, Tokyo, Japan; kondo.naoki.0s@kyoto-u.ac.jp

Received 18 May 2021 Accepted 26 October 2021

\section{Check for updates}

(C) Author(s) (or their employer(s)) 2021. Re-use permitted under CC BY-NC. No commercial re-use. See rights and permissions. Published by BMJ.

To cite: Nishioka D,
Takaku R, Kondo N. J
Epidemio/ Community Health
Epub ahead of print: [please
include Day Month Year].
doi:10.1136/jech-2021-
217296

To cite: Nishioka $D$, Takaku R, Kondo N. Epidemiol Community Health Epub ahead of print: [please 217296

\begin{abstract}
Backgrounds Income reduction in poor households affects healthcare demands for impoverished population. However, the impact of reduced benefits for public assistance recipients, who can use medical services for free, on healthcare costs has not been examined. We hypothesised that marginal cuts in benefits increase recipients' medical expenditure by extra demand for medical care. We tested this hypothesis using public assistance databases of Japan.
\end{abstract}

Methods The study population comprised households in five municipalities receiving public assistance between April 2016 and September 2018. The households have a child aged 12-60 months and receive a monthly childsupport income of US\$150, which reduces by US\$50 when the child turns 36 months of age. Our analysis comprised an age-based sharp regression-discontinuity study.

Results We observed 4893 household-months (11032 person-months). When a firstborn child reached 36 months, their frequency of outpatient visits and healthcare costs by recipients, except for the firstborn child, increased $(0.45,95 \% \mathrm{Cl}: 0.30$ to 0.61 ; US $\$ 111.2$, $95 \%$ Cl: 20.7 to 201.7 ), while those of the firstborn child did not increase significantly. The monthly medical expenditure per household increased by US $\$ 248.6$ (95\% Cl: 25.4 to 471.7$)$. Inpatient medical costs increased significantly (US\$64.3, 95\% Cl: 8.4 to 120.2).

Conclusions Government savings through income reduction were offset by increased medical expenditure. This may be due to recipients' behavioural change and their worsening health conditions. To prevent excessive medical expenditure, policymakers should consider how income reduction affects the behaviour and health of the impoverished population.

\section{INTRODUCTION}

Poverty is a known social determinant of health. ${ }^{1}$ Impoverished people have low income and their consumption is limited to their income size. Households' income can affect people's health via biological, psychological, behavioural and environmental mechanisms. ${ }^{23}$ People living in poverty have insufficient resources to meet their needs, which impedes cognitive function resulting in difficulty in making reasonable health investments. ${ }^{45}$

Therefore, ensuring basic and stable standards of income and medical services are key roles of public assistance programmes. In many countries, governments provide public assistance to ensure income stability and medical services. ${ }^{6}$ These benefit programmes have been provided through several measures (conditional/unconditional cash transfer, in-kind transfers of food and medical services), which could favourably affect recipients' health outcomes. $^{7-10}$ For example, the cluster randomised controlled trial by Fernald et $a l^{7}$ showed that a conditional cash transfer programme reduced the prevalence of being overweight and improved motor and cognitive development among poor children. Meanwhile, the systematic reviews by Sidiqqi et $a l^{9}$ concluded that cash transfer programmes benefit the health of infants, showing better birth weights and less infant mortality. However, because the income gain by these subsidies relies on the programme policies, marginal changes in subsidies occasionally occur due to the subsidising policy and the policy changes. The exogenous changes in income could influence behavioural and health problems among recipients.

While several studies on the impacts of income gain due to financial subsidising programmes have shown positive impacts on health, the studies investigating the impacts of the decline in income level on health have yielded mixed results. Some studies show that decline in income level is associated with unfavourable health conditions, ${ }^{11}{ }^{12}$ which does not hold true for all conditions that lead to income reduction. ${ }^{13-16}$ For example, mortality could reduce during an economic recession, except for suicide, potentially because decreases in time spent working results in increased time for healthy activities (eg, physical activities) and through a reduction in accidental deaths due to reduced economic activity (eg, less traffic). ${ }^{13}$ A decrease in workload could benefit health by increasing investments in health and decreasing the consumption of luxury goods that do not contribute to health. ${ }^{17}$

On the other hand, negative health effects may also occur when income decreases, accompanied by changes in individual behaviour. ${ }^{14-16}$ Income decline reduces the access to material goods to maintain health. Income decline also develops a sense of relative deprivation due to the social comparisons to those with higher incomes and with their previous living conditions, inducing psychological stress which lead to unfavourable health behaviour (eg, smoking, binge drinking, physically inactive lifestyles). ${ }^{18-20}$ These income reduction impacts should be most pronounced among those receiving public assistance due to their poor material wealth. Compared with their richer counterparts, public assistance recipients should be more 
severely affected by a reduction of income due to their limited material access, their impaired cognitive functions and their poor capacity for making rational choices, including unfavourable health behaviour and healthcare service utilisation ${ }^{4521} 22$

The amount of income subsidy can change when the conditions of recipient household change (eg, cut of childcare subsidy when a child comes to a certain age). However, if social costs (eg, healthcare covered by governmental welfare programmes) of amending these new problems due to the subsidy cut exceeds the amount saved through subsidy reduction, the efficiency of the reduction policy should be reconsidered. However, few studies have examined the effects of policy-induced income reductions on the health and health care-service use of the poorest people on public assistance. We hypothesised that a sharp policy-induced income reduction for public assistance recipients increases people's use of medical care services. We aimed to test this hypothesis by applying a quasi-experimental method, using data related to public and medical assistance claims in Japan.

\section{METHODS}

\section{Study design and participants}

This research comprises a retrospective open-cohort study. The study population included public assistance recipients in five municipalities in Japan. The households of these municipalities received additional child support income between April 2016 and September 2018. These data were sourced from public assistance databases of the municipalities' welfare offices. These databases included information concerning age, sex, number of family members, household composition and household income. Because all these data determine households' monthly subsidy of their standard minimum income, there were no missing data for our research. We also used medical assistance claims data, which showed, per monthly receipt, the total cost and number of outpatient visits. Each municipality aggregated these data using individual identification codes; the five municipalities agreed to provide us anonymised data for this study.

Japan's public assistance programme, seikatsu-hogo, is a governmental welfare programme for people who live below the poverty line and do not possess any assets; approximately 1.7\% of the population is enrolled in this programme. ${ }^{23}$ Municipality governments provide recipients with monthly minimum income protection and medical care vouchers (iryo-ken), and they are fully exempted from copayments for the use of healthcare services covered by Japan's National Health Insurance programme. ${ }^{23}$ The use of medical care vouchers has no restrictions. The size of the monthly subsidy depends on members' demographic characteristics and the socioeconomic conditions of their residential areas (eg, urbanicity, labour market conditions and standard living costs). If a household earns some income, only the difference from the standard minimum income is provided. However, if a household earns income that exceeds the standard minimum income, the household must pay the surplus as tax.

Additionally, households with children aged below 36 months receive an additional US\$150 (JPY 15 000) per child as child support. ${ }^{24}$ However, child-rearing families experience policyinduced income reduction when the child reaches the age of 36 months, as child support decreases to US\$100 (JPY 10 000) at this point until the child graduates from junior-high school. ${ }^{24}$ Taking a single-parent family in Tokyo as an example, this sharp income reduction of US\$50 (JPY 5000) represents an approximately $5 \%$ cut in household income. Using this sudden policy-induced reduction in the income of child-rearing families as a natural experiment setting, we conducted a sharp regression-discontinuity analysis on the effects of this income reduction on households' medical care expenditure.

In the standard economic theory, healthcare demand is determined based on the price of healthcare, income and opportunity costs (eg, compared with the cost of working income), as well as by other indirect costs (eg, transportation costs) for a given health status. The economic theory predicts that the effect of income on healthcare demand should be quite small and the income elasticity of healthcare demand among low-income populations would be low. ${ }^{25}$ However, it should be noted that we targeted extremely low-income populations that account for the bottom $2 \%$ of the total population. As public assistance recipients are fully exempted from the costs of national health insurance-covered medical care services, the effects of income reduction on healthcare use for the sampled population should be much larger than that supposedly for the average population.

As this study used anonymised data sourced with permission from government databases, participant consent was not required. Further, all methods were carried out in accordance with relevant guidelines and regulations of the Japanese governments.

\section{Measurement}

\section{Outcome variables}

Household healthcare costs: From the medical assistance claims data, we identified individuals' healthcare costs per month. Then, we calculated monthly healthcare costs per household by summing the individual healthcare costs for each household.

Individual number of outpatient visits per month and healthcare costs: From the medical assistance claims data, we identified the number of monthly outpatient visits and healthcare costs per individual.

Individual healthcare costs per consultation: After identifying individuals' healthcare costs, we divided the costs by the total number of outpatient visits during the same period.

\section{Explanatory variable}

Child age as a time variable: For each household, we identified the firstborn child aged within 2 years of the 36-month threshold (12-60 months) and assigned their month age to their households each month. We used this time variable as an explanatory variable.

\section{Regression model}

To investigate the impact of income reduction on medical expenditure, we applied an age-based sharp regression-discontinuity design (RDD). This design can be used when a continuous assignment variable features a threshold that determines whether individuals receive the intervention. ${ }^{26-28}$

We implemented local quadratic regression to estimate the impact of income reduction at the threshold, that is, a regression-discontinuity test. To prevent overfitting of the data and misleading impact estimation, we chose a quadratic specification rather than higher-order polynomials. ${ }^{29}$ We used a triangular kernel function to provide weight to observations near the threshold. In addition, we used the mean square error optimal bandwidth around the threshold. ${ }^{30}$ Finally, the discontinuous change at the threshold $(\tau)$ was estimated with the following model that uses age-in-months of the firstborn child $\left(m_{i t}\right)$ as an assignment variable:

$$
\tau=\lim _{m \downarrow 36} \mathrm{E}\left[Y_{i t} \mid m_{i t}=\mathrm{m}\right]-\lim _{m \uparrow 36} \mathrm{E}\left[Y_{i t} \mid m_{i t}=\mathrm{m}\right],
$$


where $Y_{\text {it }}$ denotes the expected value of the outcome for household $i$ in month age $t$.

\section{Statistical analysis}

First, we summarised the characteristics of the households for the 3 months preceding and succeeding the threshold. Second, through the regression-discontinuity test, we evaluated whether a sharp income reduction occurred at the time the firstborn child reached 36 months, using household monthly income as an outcome variable.

The identifying assumption for our RDD is that the participants are sufficiently comparable around the threshold. To check the validity of this assumption, the smoothness of their basic characteristics was examined around the time the child was 36 months of age. Specifically, continuity tests were performed for the following variables: income per household; number of family members per household; proportion of households with single parents, disabled persons and older people among the participant households; and proportion of households by municipality. Another standard test for the validity of RDD (ie, density test) was performed to verify that the assignment variables around the threshold were not manipulated. ${ }^{28}$ After checking the results of these standard tests, we performed the main analysis using monthly household healthcare costs as an outcome variable. To identify the mechanism of changes in healthcare costs, we performed additional analyses restricting outcome variables to outpatient medical, inpatient medical and pharmacy costs per household.
The mechanisms of a change in healthcare costs across the threshold were explored with the spirit following models. ${ }^{31}$ First, we separately evaluated the discontinuities of the binary decision to visit doctors in a given month. Second, we evaluated the frequency of monthly outpatient attendance that indicates recipients' spontaneous healthcare demands using the number of medical outpatient attendance per individual monthly receipt as an outcome variable. Third, we evaluated the individual healthcare costs per receipt to confirm whose healthcare costs were changed. Finally, medical care costs per outpatient attendance were used as an outcome variable to obtain suggestive evidence on how medical demand is induced by suppliers. We could use this variable as a potential supplier-induced demand on public assistance recipients because suppliers can manipulate this part to maximise their revenue (eg, excessive medical examination and treatment). ${ }^{3233}$ We conducted the second to the fourth analyses by stratifying household members, that is, firstborn children and all other family members (ie, parents, grandparents and other relatives).

Finally, for the robustness check, we performed four sensitivity analyses. First, we applied placebo tests using artificial cutoffs in each month in the absence of any systematic income reduction. Second, to address potential biases induced by behavioural changes on the part of the recipients around the threshold of the regression-discontinuity estimation, we performed a 'donut hole' test. ${ }^{28}$ We removed the 2-month observations from both sides of the threshold, which might have been impacted by manipulation, and then repeated the estimation and inference analysis using

Table 1 Characteristics of the households and their healthcare costs in the 3 months preceding and succeeding the threshold

\begin{tabular}{|c|c|c|c|c|c|c|c|}
\hline & Months-age & & & & & & \\
\hline Character & 33 & 34 & 35 & 36 & 37 & 38 & 39 \\
\hline $\begin{array}{l}\text { Number of households (number of households with } \\
\text { healthcare costs above zero) }\end{array}$ & $96(95)$ & 107 (103) & $95(92)$ & $106(99)$ & $100(93)$ & 107 (103) & $114(107)$ \\
\hline $\begin{array}{l}\text { Number of people in each household } \\
\text { Mean (SD) }\end{array}$ & $3.2(1.3)$ & $3.2(1.3)$ & $3.4(1.4)$ & $3.4(1.7)$ & $3.3(1.3)$ & $3.3(1.4)$ & $3.2(1.3)$ \\
\hline \multicolumn{8}{|l|}{ Types of households } \\
\hline With single-parent & $63(65.6 \%)$ & $66(61.7 \%)$ & $63(66.3 \%)$ & $70(66.0 \%)$ & $61(61.0 \%)$ & $68(63.6 \%)$ & $79(69.3 \%)$ \\
\hline With disabled person & $2(2.1 \%)$ & $2(1.9 \%)$ & $2(2.1 \%)$ & $2(1.9 \%)$ & $1(1.0 \%)$ & $2(1.9 \%)$ & $1(0.9 \%)$ \\
\hline With older people & $13(13.5 \%)$ & $11(10.3 \%)$ & $12(12.6 \%)$ & $11(10.4 \%)$ & $11(11.0 \%)$ & $11(10.3 \%)$ & $14(12.3 \%)$ \\
\hline Others & $18(18.8 \%)$ & $28(26.2 \%)$ & $18(18.9 \%)$ & $23(21.7 \%)$ & $27(27.0 \%)$ & $26(24.3 \%)$ & $20(17.5 \%)$ \\
\hline $\begin{array}{l}\text { Monthly household income (US\$) } \\
\text { Mean (SD) }\end{array}$ & $1551.3(615.8)$ & $1520.9(617.6)$ & $1532.5(616.2)$ & $1488.6(649.9)$ & $1488.9(547.8)$ & $1484.6(576.9)$ & $1482.1(571.0)$ \\
\hline $\begin{array}{l}\text { Monthly healthcare costs per household (US\$) } \\
\text { Mean (SD) }\end{array}$ & $485.7(951.6)$ & $309.2(337.6)$ & $358.3(380.7)$ & $461.9(1146.2)$ & $601.3(1288.7)$ & $674.5(1391.8)$ & $575.0(1248.8)$ \\
\hline Monthly total healthcare costs (US\$) & 46631.0 & 33083.3 & 34039.5 & 48958.2 & 60130.0 & 72168.3 & 65548.9 \\
\hline Medical outpatient & $\begin{array}{l}18156.5 \\
(38.9 \%)\end{array}$ & $\begin{array}{l}13118.2 \\
(39.7 \%)\end{array}$ & $\begin{array}{l}9322.8 \\
(27.4 \%)\end{array}$ & $\begin{array}{l}23833.9 \\
(48.7 \%)\end{array}$ & $\begin{array}{l}17879.0 \\
(29.7 \%)\end{array}$ & $\begin{array}{l}28409.8 \\
(39.4 \%)\end{array}$ & $\begin{array}{l}25402.2 \\
(38.8 \%)\end{array}$ \\
\hline Medical Inpatient & $\begin{array}{l}7445.1 \\
(16.0 \%)\end{array}$ & $\begin{array}{l}4132.1 \\
(12.5 \%)\end{array}$ & $\begin{array}{l}0 \\
(0 \%)\end{array}$ & $\begin{array}{l}1551.6 \\
(3.2 \%)\end{array}$ & $\begin{array}{l}19173.3 \\
(31.9 \%)\end{array}$ & $\begin{array}{l}22958.0 \\
(31.8 \%)\end{array}$ & $\begin{array}{l}9954.1 \\
(15.2 \%)\end{array}$ \\
\hline Dental & $\begin{array}{l}4559.9 \\
(9.8 \%)\end{array}$ & $\begin{array}{l}6332.9 \\
(19.1 \%)\end{array}$ & $\begin{array}{l}5870.5 \\
(17.2 \%)\end{array}$ & $\begin{array}{l}3824.9 \\
(7.8 \%)\end{array}$ & $\begin{array}{l}5007.0 \\
(8.3 \%)\end{array}$ & $\begin{array}{l}7884.4 \\
(10.9 \%)\end{array}$ & $\begin{array}{l}8305.7 \\
(12.7 \%)\end{array}$ \\
\hline Pharmacy & $\begin{array}{l}9387.5 \\
(20.1 \%)\end{array}$ & $\begin{array}{l}9500.1 \\
(28.7 \%)\end{array}$ & $\begin{array}{l}18846.2 \\
(55.4 \%)\end{array}$ & $\begin{array}{l}9253.8 \\
(18.9 \%)\end{array}$ & $16235.7(27.0 \%)$ & $\begin{array}{l}12916.1 \\
(17.9 \%)\end{array}$ & $\begin{array}{l}12921.9 \\
(19.7 \%)\end{array}$ \\
\hline Visiting nurses and nursing homes & $\begin{array}{l}7082.0 \\
(15.2 \%)\end{array}$ & $\begin{array}{l}0 \\
(0 \%)\end{array}$ & $\begin{array}{l}0 \\
(0 \%)\end{array}$ & $\begin{array}{l}10494.0 \\
(21.4 \%)\end{array}$ & $\begin{array}{l}1835.0 \\
(3.1 \%)\end{array}$ & $\begin{array}{l}0 \\
(0 \%)\end{array}$ & $\begin{array}{l}8965.0 \\
(13.7 \%)\end{array}$ \\
\hline \multicolumn{8}{|l|}{ Municipality } \\
\hline A & $2(2.1 \%)$ & $5(4.7 \%)$ & $2(2.1 \%)$ & $5(4.7 \%)$ & $3(3.0 \%)$ & $1(0.9 \%)$ & $4(3.5 \%)$ \\
\hline B & $5(5.2 \%)$ & $8(7.5 \%)$ & $5(5.3 \%)$ & $9(8.5 \%)$ & $11(11.0 \%)$ & $9(8.4 \%)$ & $6(5.3 \%)$ \\
\hline c & $8(8.3 \%)$ & $6(5.6 \%)$ & $9(9.5 \%)$ & $12(11.3 \%)$ & $8(8.0 \%)$ & $11(10.3 \%)$ & $11(9.6 \%)$ \\
\hline D & $36(37.5 \%)$ & $40(37.4 \%)$ & $39(41.1 \%)$ & $35(33.0 \%)$ & $36(36.0 \%)$ & $41(38.3 \%)$ & $49(43.0 \%)$ \\
\hline E & $45(46.9 \%)$ & $48(44.9 \%)$ & $40(42.1 \%)$ & $45(42.5 \%)$ & $42(42.0 \%)$ & $45(42.1 \%)$ & $44(38.6 \%)$ \\
\hline
\end{tabular}

'Monthly total healthcare costs' were calculated by summing up the all-households' healthcare costs in each month. 'Monthly healthcare costs per household' was calculated by dividing the 'Monthly total healthcare costs' by the number of the households included in each month. 
80000

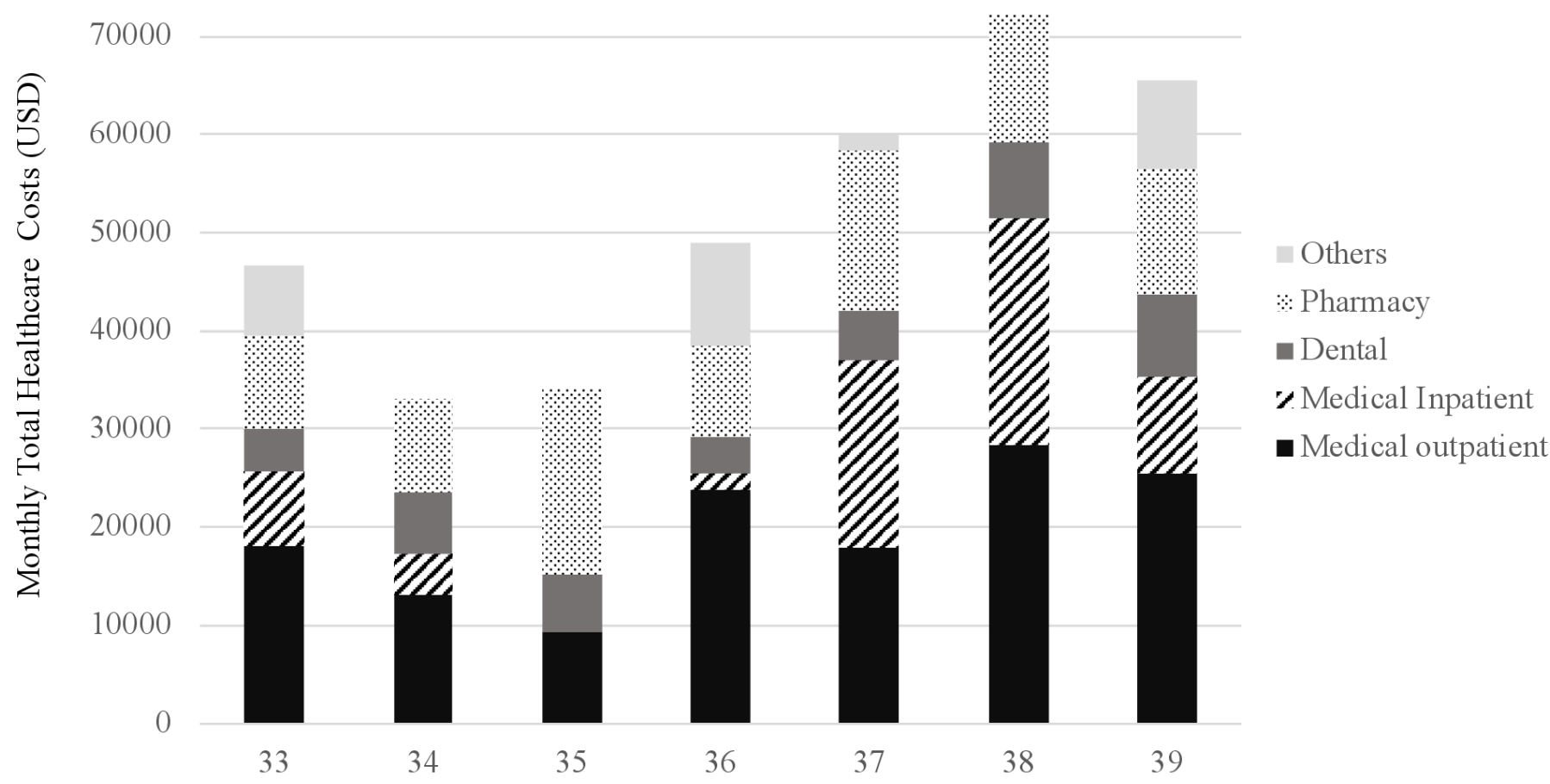

Age in month of the firstborn children

Figure 1 Breakdown of the monthly total medical expenditure in terms of the firstborn child's age in months.

the remaining sample. Third, as a robustness check, we examined the magnitude and precision of the impact estimates over multiple bandwidths and different specifications of the running variables. ${ }^{28}$ Fourth, we have conducted another set of analyses using log-transformed households healthcare costs considering the skewness of healthcare costs among the study population on healthcare. ${ }^{34}$ All analyses were performed using the 'rddensity' and 'rdrobust' commands on Stata/SE V.16.1 (Stata Corp). ${ }^{28}$

\section{RESULTS}

We observed a total of 4893 household-months (11032 personmonths). A total of 476 households were unique households,

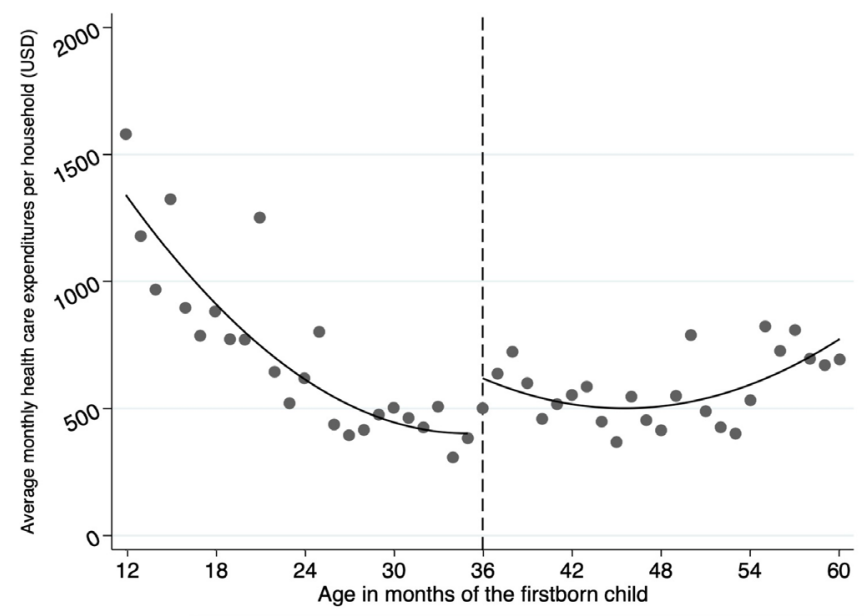

Figure 2 Average monthly medical expenditure per household in terms of the firstborn child's age in months. and 63 households were on public assistance throughout the study period. The remaining 413 households were observed 10.3 months (mean) (online supplemental table 1). There were 106 households at the threshold. Among these, the mean number of people in a household was $3.4(\mathrm{SD}=1.7) ; 66.0 \%$ were single-parent households without any other family members, while $10.4 \%$ included older people (three-generation family). The mean medical expenditure per household was US\$461.9 $(S D=1146.2)$ (table 1). The breakdown of the monthly total medical expenditure is shown in figure 1 .

We could confirm an income reduction at the threshold age (regression-discontinuity estimate: US\$-56.7). However, the estimate was not consistent with US $\$ 50$ because the households included before and after the threshold were not completely same. The results of the continuity test showed that the characteristics of individuals and households were consistent around the threshold (online supplemental table 2). We failed to reject the null hypothesis of a smooth density across the threshold $(p=0.70$, online supplemental figure 1$)$. These findings suggest that the assignment variables were not manipulated.

The mean medical expenditure of child-rearing recipient households continued to decrease after the firstborn child reached 12 months; however, we observed a sharp upward jump across the threshold. The result of the regression-discontinuity test showed that, when the firstborn child reached 36 months, the monthly medical expenditure per household increased by US\$248.6 (95\% CI: 25.4 to 471.7; figure 2, table 2). Monthly inpatient medical costs per household increased by US $\$ 64.3(95 \%$ CI: 8.4 to 120.2). Outpatient medical costs (US\$96.7, 95\% CI: -0.5 to 193.9 ) and pharmacy costs (US\$49.8, 95\% CI -31.0 to 130.5 ) also showed increases in point estimates (table 2). All sensitivity analyses supported the results of our main analyses. We found no impact on the placebo tests, which confirmed 
Table 2 Results of the main regression-discontinuity (RD) model and models exploring mechanisms

\begin{tabular}{lll}
\hline & RD estimator & $95 \% \mathrm{Cl}$ \\
\hline $\begin{array}{l}\text { Main analysis } \\
\text { Households' total healthcare costs (US\$) }\end{array}$ & 248.6 & 25.4 to 471.7 \\
\hline $\begin{array}{l}\text { Mechanisms } \\
\text { Breakdown of healthcare costs }\end{array}$ & \\
\hline $\begin{array}{l}\text { Inpatient medical costs (US\$) } \\
\text { Outpatient medical costs (US\$) }\end{array}$ & 64.3 & 8.4 to 120.2 \\
\hline $\begin{array}{l}\text { Pharmacy costs (US\$) } \\
\text { Proportions of recipients on healthcare in each month } \\
\text { (\%) }\end{array}$ & 96.7 & -0.5 to 193.9 \\
\hline \begin{tabular}{l} 
Individual frequency of medical outpatient attendance per receipt \\
\hline Firstborn child
\end{tabular} & 0.03 & -31.0 to 130.5 \\
\hline $\begin{array}{l}\text { Recipients other than the firstborn child } \\
\text { Individual healthcare costs per receipt (US\$) }\end{array}$ & 0.45 & -1.1 to 5.8 \\
\hline $\begin{array}{l}\text { Firstborn child } \\
\text { Recipients other than the firstborn child }\end{array}$ & 25.0 & 0.30 to 0.61 \\
\hline $\begin{array}{l}\text { Medical care costs per outpatient attendance (US\$) } \\
\text { Firstborn child }\end{array}$ & 111.2 & -9.0 to 59.0 \\
\hline Recipients other than the firstborn child & -20.9 & 20.7 to 201.7 \\
\hline
\end{tabular}

that the intervention assignment was exogenous (online supplemental table 3). Furthermore, the donut hole tests showed that systematic bias caused by a non-random behavioural change did not exist (online supplemental table 4). The estimations obtained by applying multiple bandwidths and different specifications of the running variables to our regression equations were consistent with our main analysis findings (online supplemental tables 5 and 6). The result of the regression-discontinuity test using logtransformed household healthcare costs supported the results of our original analysis (ie, coef. $0.15,95 \% \mathrm{CI}$ : 0.02 to 0.28 ) (online supplemental figure 2).

By exploring the mechanisms of a change in healthcare costs across the threshold, we found that the estimate of changes in proportion of recipients who visited doctors was 2.4\% (95\% CI: $-1.1 \%$ to $5.8 \%$; table 2 ). The frequency of outpatient visits per month increased among family members except for firstborn children (coef.: 0.45 , 95\% CI: 0.30 to 0.61 ), but did not increase among firstborn children (coef.: 0.03, 95\% CI: -0.17 to 0.22 ; table 2). The individual healthcare costs, except for firstborn child, increased by US\$111.2 (95\% CI: 20.7 to 201.7), while those for firstborn children did not increase significantly (US\$25.0, 95\% CI: -9.0 to 59.0; table 2). For both the firstborn children and family members (except for firstborn children), healthcare costs per consultation did not change across the threshold (coef.: US\$4.2, 95\% CI: -6.2 to 14.6; coef.: US\$ -20.9 , 95\% CI: -75.6 to 33.9 , respectively; table 2 ).

\section{DISCUSSION}

In this study, we investigated the relationship between sharp income reduction and healthcare expenditure among public assistance recipients. We found that government savings through income reduction were offset by increased healthcare costs, paradoxically resulting in a greater financial burden for municipalities. A significant increase in inpatient costs, which can be attributed to an increase in the frequency of outpatient visits and individual healthcare costs among recipients, except for the firstborn children (ie, adult recipients).

Based on the results, we considered two mechanisms of the relationship between sharp income reduction and increased medical care costs among public assistance recipients. First, adult recipients may be driven to use healthcare services within a month after their income reduction. This immediate response may be partially explained by behavioural changes among them, which were shown by an increase in the frequency of outpatient attendance. For example, adult recipients who experienced income reduction from a minimum standard of living may not be able to adequately spend their money on resources for treating their illness (ie, over-the-counter medications). Hence, they rely on medical care that can be received without any payment at medical institutions. Second, because public assistance recipients were likely to have more avoidable multiple chronic diseases (as known to be ambulatory care sensitive conditions), ${ }^{21} 2235$ physical and psychological stress may worsen their health conditions, which potentially increase the healthcare costs, especially for inpatients costs. These stresses caused by financial worries and psychological strains after the subsidy cut; changes in diet (eg, consumption of cheap fast food) and under-nutrition due to income reduction ${ }^{36}$ may induce acute stress-related symptoms and diseases (eg, asthma, headache and diabetes). ${ }^{37}$ These symptoms may accelerate recipients' consultation frequency and hospitalisation. Anxiety induced by income reduction may also lead them to seek emotional support from healthcare professionals despite the absence of an actual medical need. The results showing an increase in inpatient medical costs emphasise the need to pay close attention to changes in recipients' health.

To prevent excessive medical expenditure, policymakers should consider how reductions in income subsidies affect recipients' behaviour and health, including the necessity of additional material support that can compensate for their scarcity. Our results indicate that reducing benefits for the poor members of society who receive public assistance can result in increased medical expenditure that exceeds the reduction in benefits.

\section{What is already known on this subject}

In the standard economic theory, demand for healthcare is determined by the price of healthcare, income and opportunity costs (eg, compared with the cost of childrearing burden or working income), as well as by other indirect costs (eg, transportation) for a given health status. Although income reduction in poor households affects healthcare demands, conventional economic theories have predicted that the effect of income on the demand for healthcare is quite small. However, the impact of reduced benefits for public assistance recipients (extremely lowincome populations that account for the bottom $2 \%$ of the total), who can use medical services for free, on healthcare costs has not been examined.

\section{What this study adds}

Among recipients of public assistance, unlike the conventional theories in economics, marginal reductions in cash benefits may be offset by increased medical expenditure. This may be due to recipients' behavioural change and their worsening health conditions. To prevent excessive medical expenditure, policymakers should consider how income reduction affects the behaviour and health of the impoverished population. 
Sharp income reduction for public assistance recipients occurs as a result of, for example, policy change at the macro-level, decreases in family size (eg, through a divorce, bereavement or children becoming independent), and expiration of public assistance at the micro-level. If our findings can be replicated in other countries, policymakers and medical care providers should pay more attention to recipients' health and healthcare costs when implementing sharp income reductions. Such extra consideration and consequent reformulation of policies may benefit both the patients' and governments' financial statuses.

There are several limitations to this study. First, although we confirmed the continuities of many possible factors, we may have overlooked other exogenous factors. Notable events that coincided with the threshold were kindergarten or nursery admission and health checkups for children aged 3 years. However, such admission occurs at the age of 36-47 months, while health checkups are provided at the age of 39-42 months in the study municipalities. Thus, we could not regard these as exogenous events at the study threshold ( 36 month age). This is also supported by our finding that no change was observed in outpatient attendance and healthcare costs among firstborn children. In fact, among the general population, healthcare use and healthcare costs do not increase at the age of three. ${ }^{38}$ Second, we cannot disregard the possibility that chance deteriorations in recipients' health at the threshold coincidently increased healthcare costs. There could be critical periods for being exposed to the specific disease risks, resulting in the disease incidence in a specific time in the life course. ${ }^{39}$ However, our findings showed that the healthcare costs among the firstborn child did not increase at the point of subsidy cuts, the critical periods mechanisms were not likely to explain our findings. Third, because the conducted study was open cohort, both the participation and the attrition during the study period by same households may occur. Some households did not experience the income reduction, this may bias our findings. However, the characteristics between the households migrated in/out and those on public assistance throughout the study periods were similar (online supplemental table 1). The results of continuity and density tests also showed that no significant differences in the study participants across the threshold exist. Therefore, this bias unlikely affect the study results critically. Fourth, the generalisability of our findings is limited because this study only used data from five municipalities in Japan (online supplemental table 7).

In summary, reduction in public assistance benefits may cause healthcare utilisation offsets among recipients of public assistance. Future studies should identify the materialistic, behavioural and psychosocial factors driving this observed association and test the generalisability of our findings.

\section{Twitter Daisuke Nishioka @DiceNish and Naoki Kondo @naoki_kondo}

Acknowledgements We thank Hideki Hashimoto, Yasuki Kobayashi, Jun Tomio, Takuma Sugahara and Wataru Suzuki for their helpful comments and support regarding the analysis and data interpretation. This study was presented at the 15th Annual Conference held by the Japan Health Economics Association (2020). We also thank Editage (http://www.editage.com) for editing and reviewing this manuscript.

Contributors DN, RT and NK conceptualised and designed the study. DN analysed the data and prepared the manuscript. NK finalised the manuscript and is the guarantor. All authors read and approved the final manuscript.

Funding This study was supported by the Japan Society for the Promotion of Science KAKENHI grants (grant numbers: 17K19793, 18 H04071 and 20K20774), Institute for Health Economics and Policy (grant number: N/A), KITACOM (grant number: N/A), and Japan Medical Association (grant number: N/A). These funding bodies had no discretion and involvement in our study protocol, analysis, interpretation of the results or submission of this manuscript.
Competing interests DN and RT declare no competing interests associated with this manuscript. NK conducted collaborative research with Kitanihon Computer Service (KITACOM) that provided the data used in the present study. NK received a research fund and a scholarship donation from KITACOM.

Patient consent for publication Not applicable.

Ethics approval The study protocol was approved by the Ethics Committee of the Graduate School of Medicine of the University of Tokyo (Approval No: 11503).

Provenance and peer review Not commissioned; externally peer reviewed.

Data availability statement Data are available upon reasonable request. Data are available with the permission of the municipalities.

Supplemental material This content has been supplied by the author(s). It has not been vetted by BMJ Publishing Group Limited (BMJ) and may not have been peer-reviewed. Any opinions or recommendations discussed are solely those of the author(s) and are not endorsed by BMJ. BMJ disclaims all liability and responsibility arising from any reliance placed on the content. Where the content includes any translated material, BMJ does not warrant the accuracy and reliability of the translations (including but not limited to local regulations, clinical guidelines, terminology, drug names and drug dosages), and is not responsible for any error and/or omissions arising from translation and adaptation or otherwise.

Open access This is an open access article distributed in accordance with the Creative Commons Attribution Non Commercial (CC BY-NC 4.0) license, which permits others to distribute, remix, adapt, build upon this work non-commercially, and license their derivative works on different terms, provided the original work is properly cited, appropriate credit is given, any changes made indicated, and the use is non-commercial. See: http://creativecommons.org/licenses/by-nc/4.0/.

\section{ORCID iDs}

Daisuke Nishioka http://orcid.org/0000-0002-3116-1195

Naoki Kondo http://orcid.org/0000-0002-6425-6844

\section{REFERENCES}

1 Marmot M, Friel S, Bell R, et al. Closing the gap in a generation: health equity through action on the social determinants of health. Lancet 2008;372:1661-9.

2 Marmot M. The influence of income on health: views of an epidemiologist. Health Aff 2002;21:31-46.

3 Kawachi I, Kennedy BP. Income inequality and health: pathways and mechanisms. Health Serv Res 1999;34:215-27.

4 Mullainathan S, Eldar S. Scarcity: why having too little means so much. London: Macmillan, 2013

5 Mani A, Mullainathan S, Shafir E, et al. Poverty impedes cognitive function. Science 2013:341:976-80

6 World Health Organization. A conceptual framework for action on the social determinants of health, 2010. Available: https://www.who.int/sdhconference/ resources/ConceptualframeworkforactiononSDH_eng.pdf

7 Fernald LCH, Gertler PJ, Neufeld LM. Role of cash in conditional cash transfer programmes for child health, growth, and development: an analysis of Mexico's Oportunidades. Lancet 2008;371:828-37.

8 Milligan K, Stablie M. Child benefits, maternal employment, and children's health: evidence from canadian child benefit expansions. Am Econ Rev 2009:99:128-32.

9 Siddiqi A, Rajaram A, Miller SP. Do cash transfer programmes yield better health in the first year of life? A systematic review linking low-income/middle-income and highincome contexts. Arch Dis Child 2018:103:920-6.

10 Pega F, Liu SY, Walter S, et al. Unconditional cash transfers for assistance in humanitarian disasters: effect on use of health services and health outcomes in lowand middle-income countries. Cochrane Database Syst Rev 2015;63.

11 Chetty R, Stepner M, Abraham S, et al. The association between income and life expectancy in the United States, 2001-2014. JAMA 2016;315:1750-66.

12 Kinge JM, Modalsli JH, Øverland S, et al. Association of household income with life expectancy and cause-specific mortality in Norway, 2005-2015. JAMA 2019:321:1916-25.

13 Ruhm CJ. Are recessions good for your health? Q J Econ 2000;115:617-50.

14 Bickel WK, Wilson AG, Chen C, et al. Stuck in time: negative income shock constricts the temporal window of valuation spanning the future and the past. PLoS One 2016;11:e0163051

15 Mellis AM, Snider SE, Bickel WK. Narrative theory: II. self-generated and experimenterprovided negative income shock narratives increase delay discounting. Exp Clin Psychopharmacol 2018;26:113-8.

16 Mellis AM, Athamneh LN, Stein JS, et al. Less is more: negative income shock increases immediate preference in cross commodity discounting and food demand. Appetite 2018;129:155-61.

17 Grossman M. The demand for health: a theoretical and empirical investigation. Columbia university press, 1972. JSTOR. Available: www.jstor.org/stable/10.7312/ gros17900. Accessed 22 July 2021 
18 Runciman WG, Runciman B. Relative deprivation and social justice: a study of attitudes to social inequality in twentieth-century England. Vol. 13. Berkeley: University of California Press, 1966.

19 Kondo N, Saito M, Hikichi H, et al. Relative deprivation in income and mortality by leading causes among older Japanese men and women: ages cohort study. J Epidemiol Community Health 2015;69:680-5.

20 Adjaye-Gbewonyo K, Kawachi I. Use of the Yitzhaki index as a test of relative deprivation for health outcomes: a review of recent literature. Soc Sci Med 2012;75:129-37.

21 Ministry of Health, Labor, and Welfare. Appropriate medical assistance and health management for people on public assistance (in Japanese), 2017. Available: https:// www.mhlw.go.jp/file/05-Shingikai-12601000-Seisakutoukatsukan-Sanjikanshitsu_ Shakaihoshoutantou/0000169132_5.pdf

22 Yamada A, Shikata M. Structural change in old-age poverty and the decrease in expenditures due to the abolishment of the old age supplement for public assistance. Quarterly Journal of Social Security Research 2016;1:399-417.

23 Sakamoto H, Rahman M, Nomura S, et al. Japan health system review, 2018. Available: https://apps.who.int/iris/handle/10665/259941

24 Ministry of Health Labour and Welfare. Support and additional allowance for households with children on public assistance (in Japanese), 2021. Available: https:// www.mhlw.go.jp/file/05-Shingikai-12601000-Seisakutoukatsukan-Sanjikanshitsu_ Shakaihoshoutantou/26102104_6.pdf

25 Phelps CE. Health economics. 5th ed. Boston: Routledge, 2016.

26 Imbens GW, Lemieux T. Regression discontinuity designs: a guide to practice. J Econom 2008;142:615-35.

27 Moscoe E, Bor J, Bärnighausen T. Regression discontinuity designs are underutilized in medicine, epidemiology, and public health: a review of current and best practice. $J$ Clin Epidemiol 2015;68:132-43.

28 Cattaneo MD, Idrobo N, Titiunik R. Elements in quantitative and computational methods for the social sciences. Cambridge: Cambridge University Press, 2020.
29 Gelman A, Imbens G. Why high-order polynomials should not be used in regression discontinuity designs. Journal of Business \& Economic Statistics 2019;37:447-56.

30 Imbens G, Kalyanaraman K. Optimal bandwidth choice for the regression discontinuity estimator. Rev Econ Stud 2012;79:933-59.

31 Duan N, Manning WG, Morris CN. A comparison of alternative models for the demand for medical care. J Bus Econ Stat 1983;1:115-26.

32 Kadoya Y, Kodera T. Market competition and Supplier-Induced demands: analyzing medical expense from Micro-Data in Japan. Japanese Journal of Health Economics and Policy 2013;25:114-25.

33 Evans RG. Supplier-induced demand: some empirical evidence and implications. In: Perlman M, ed. The economics of health and medical care. Berlin: Springer, 1974.

34 Mihaylova B, Briggs A, O'Hagan A, et al. Review of statistical methods for analysing healthcare resources and costs. Health Econ 2011;20:897-916.

35 Longman JM, Passey ME, Ewald DP, et al. Admissions for chronic ambulatory care sensitive conditions - a useful measure of potentially preventable admission? BMC Health Serv Res 2015;15:472.

36 Tanumihardjo SA, Anderson C, Kaufer-Horwitz M, et al. Poverty, obesity, and malnutrition: an international perspective recognizing the paradox. J Am Diet Assoc 2007; 107:1966-72.

37 Brantley PJ, Jones GN. Daily stress and stress-related disorders. Ann Behav Med 1993;15:17-25.

38 Ministry of Health, Labor, and Welfare. Survey of medical benefits (in Japanese), 2017. Available: https://www.mhlw.go.jp/stf/seisakunitsuite/bunya/iryouhoken/database/ zenpan/iryoukyufu.html

39 Ben-Shlomo Y, Kuh D. A life course approach to chronic disease epidemiology: conceptual models, empirical challenges and interdisciplinary perspectives. Oxford: Oxford University Press, 2002. 